\title{
Crystal Structure and Regulation Mechanisms of the CyaB Adenylyl Cyclase from the Human Pathogen Pseudomonas aeruginosa
}

\author{
Hüsnü Topal ${ }^{1}$, Nanette B. Fulcher ${ }^{2}$, Jacob Bitterman ${ }^{3}$, Eric Salazar ${ }^{3}$, Jochen Buck ${ }^{3}$, Lonny \\ R. Levin ${ }^{3}$, Martin J. Cann ${ }^{4}$, Matthew C. Wolfgang ${ }^{2,5}$, and Clemens Steegborn ${ }^{6,}{ }^{*}$ \\ ${ }^{1}$ Department of Physiological Chemistry, Ruhr-University Bochum, Germany \\ ${ }^{2}$ Cystic Fibrosis/Pulmonary Research and Treatment Center, University of North Carolina, Chapel \\ Hill, North Carolina, USA \\ ${ }^{3}$ Department of Pharmacology, Weill Medical College of Cornell University, New York, USA \\ ${ }^{4}$ School of Biological and Biomedical Sciences, Durham University, United Kingdom \\ ${ }^{5}$ Department of Microbiology and Immunology, University of North Carolina, Chapel Hill, North \\ Carolina, USA \\ ${ }^{6}$ Department of Biochemistry, University of Bayreuth, Germany
}

\begin{abstract}
Pseudomonas aeruginosa is an opportunistic bacterial pathogen and major cause of healthcareassociated infections. While the organism's intrinsic and acquired resistance to most antibiotics hinders treatment of $P$. aeruginosa infections, the regulatory networks controlling its virulence provide novel targets for drug development. $\mathrm{CyaB}$, a key regulator of $P$. aeruginosa virulence, belongs to the Class III adenylyl cyclase (AC) family of enzymes that synthesize the second messenger cyclic adenosine $3^{\prime}, 5^{\prime}$-monophosphate (cAMP). These enzymes consist of a conserved catalytic domain fused to one or more regulatory domains. We describe here the biochemical and structural characterization of $\mathrm{CyaB}$ and its inhibition by small molecules. We show that $\mathrm{CyaB}$ belongs to the Class IIIb subfamily and, like other subfamily members, its activity is stimulated by inorganic carbon. $\mathrm{CyaB}$ is also regulated by its $\mathrm{N}$-terminal MASE2 domain, which acts as a membrane anchor. Using a genetic screen, we identified activating mutations in CyaB. By solving the crystal structure of the $\mathrm{CyaB}$ catalytic domain, we rationalized the effects of these mutations and propose that $\mathrm{CyaB}$ employs regulatory mechanisms similar to other Class III ACs. The CyaB structure further indicates subtle differences compared to other Class III ACs in both the active and inhibitor binding pocket. Consistent with these differences, we observed a unique inhibition profile, including identification of a $\mathrm{CyaB}$ selective compound. Overall, our results reveal mechanistic details of the physiological and pharmacological regulation of $\mathrm{CyaB}$ and provide the basis for its exploitation as a therapeutic drug target.
\end{abstract}

(C) 2011 Elsevier Ltd. All rights reserved.

*Correspondence should be addressed to: Clemens Steegborn, University of Bayreuth, Dept. of Biochemistry, Universitätsstr. 30, 95447 Bayreuth, Germany; phone: (49)(921)552421; fax: (49)(921)552432; Clemens.Steegborn@uni-bayreuth.de.

ACCESSION NUMBERS: Coordinates and structure factors for the crystalstructure of CyaB have been deposited with the Protein Data Bank under accession code 3R5G.

Publisher's Disclaimer: This is a PDF file of an unedited manuscript that has been accepted for publication. As a service to our customers we are providing this early version of the manuscript. The manuscript will undergo copyediting, typesetting, and review of the resulting proof before it is published in its final citable form. Please note that during the production process errors may be discovered which could affect the content, and all legal disclaimers that apply to the journal pertain. 


\section{Keywords}

Class III; adenylyl cyclase; inhibition; activation; regulation mechanism

\section{INTRODUCTION}

Pseudomonas aeruginosa is a common cause of nosocomial and community-acquired pneumonia, and the primary cause of mortality in individuals with cystic fibrosis $1 ; 2$. Treatment of $P$. aeruginosa infections is handicapped by the bacterium's high intrinsic and acquired antibiotic resistance ${ }^{3}$, which has left few effective treatment options ${ }^{4}$. The regulatory networks controlling $P$. aeruginosa virulence gene expression represent novel targets for drug development. Multiple $P$. aeruginosa virulence systems are controlled by the second messenger cyclic adenosine $3^{\prime}, 5^{\prime}$-monophosphate (cAMP) via the cAMPdependent global transcriptional regulator $\mathrm{Vfr} 5 ; 6 ; 7$. cAMP is formed by adenylyl cyclase (AC), and $P$. aeruginosa has three such enzymes. ACs can be grouped into six evolutionary distinct classes ${ }^{8 ; 9}$. P. aeruginosa ExoY belongs to Class II ${ }^{10}$, a small group of secreted bacterial ACs that act as toxins. The two other $P$. aeruginosa ACs, CyaA and CyaB, belong to Class I and III, respectively. Class I enzymes are found exclusively in bacteria and are best known for their role in regulating nutrient utilization ${ }^{8}$. As yet, the role of $P$. aeruginosa CyaA is unknown. Class III is the largest family, which comprises members in almost all organisms including all mammalian ACs and guanylyl cyclases (GCs). Class III ACs have diverse cellular functions, including regulation of virulence mechanisms in several microbial pathogens. In $P$. aeruginosa, CyaB activity indeed accounts for the majority of intracellular cAMP and only $\mathrm{CyaB}$ is essential for $P$. aeruginosa colonization and dissemination in a mouse model of acute pneumonia ${ }^{11}$. CyaB activity appears to be triggered by environmental signals and we recently showed that $\mathrm{CyaB}$ is regulated by the Chp chemotaxis-like chemosensing system ${ }^{12}$; however, the exact environmental trigger and activation mechanisms remain to be identified.

Class III ACs possess one or more regulatory domains fused to the AC catalytic domain ${ }^{13 ; 14}$. Two catalytic domains, either from two polypeptides or from a single protein chain, form a (pseudo)dimeric $\mathrm{C}_{1} \mathrm{C}_{2}$ catalytic core. A variety of Class III crystal structures $15 ; 16 ; 17 ; 18$ demonstrate that both monomers contribute conserved catalytic residues to the two active sites at the dimer interface. Two catalytic $\mathrm{Mg}^{2+}$ ions are coordinated by two Asp residues from $\mathrm{C}_{1}$, and the transition state is stabilised by an Asp-Arg pair from $\mathrm{C}_{2}{ }^{9 ; 19}$. Nucleotide specificity is primarily determined by a Lys from $\mathrm{C}_{1}$ and an Asp from $\mathrm{C}_{2}$, which bind to the ATP base ${ }^{9 ; 18}$. CyaB belongs to the Class III subgroup $\mathrm{IIIb}^{20}$, where this Asp is exchanged for a Thr. This feature appears to correlate with sensitivity to inorganic carbon; i.e., the constituents of dissolved carbon dioxide $\left(\mathrm{CO}_{2}\right)$, including bicarbonate $\left(\mathrm{HCO}_{3}{ }^{-}\right)$, carbonic acid, and carbonate (from now on referred to as $\mathrm{CO}_{2} / \mathrm{HCO}_{3}{ }^{-}$). Stimulation by $\mathrm{CO}_{2} / \mathrm{HCO}_{3}{ }^{-}$was first reported for the catalytic core of mammalian soluble adenylyl cyclase (sAC), and subsequently for catalytic domains of other, microbial "sAC-like" IIIb enzymes $16 ; 21 ; 22$. Although $\mathrm{CO}_{2} / \mathrm{HCO}_{3}{ }^{-}$activation is unique for "sAC"-like ACs, the molecular mechanisms involved are assumed to share similarities with regulation by other stimuli, such as G-proteins or $\mathrm{pH}$, and to be based on the relative rotation of catalytic domains and transitions between open and closed active site conformations ${ }^{15 ; 16 ; 23 .}$.

In $\mathrm{CyaB}$, the catalytic domain is fused to an N-terminal MASE2 (membrane associated sensor 2) domain ${ }^{24}$. MASE2 is a predicted transmembrane module found in a limited number of bacterial Class III ACs and diguanylyl cyclases. MASE2 domains are assumed to serve as sensors for environmental signals, relaying the signal to the cytosol by regulating 
the activity of the fused catalytic domain. However, the exact roles of MASE2 domains in general and in $\mathrm{CyaB}$ in particular remain to be revealed.

Their role in virulence regulation renders microbial ACs interesting drug targets. In the fungal pathogen Cryptococcus neoformans, a $\mathrm{CO}_{2}$-sensing $\mathrm{AC}$ regulates virulence, and interfering with this system prevents virulent growth ${ }^{25 ; 26}$. Interestingly, the regulation of Class IIIb ACs correlates with the sensitivity to established AC inhibitors: Class IIIb enzymes are sensitive to the synthetic compounds $\mathrm{KH} 7$ and BCC2/8, whereas other Class III ACs show a higher sensitivity to so-called P-site inhibitors, nucleotide derivatives which block the substrate binding pocket $9 ; 27 ; 28 ; 29$. It thus appears that specific inhibition of microbial ACs can be achieved and insights into the molecular details of the physiological and pharmacological regulation of such enzymes are an important step toward anti-infective compounds with novel mechanisms of action.

Here, we describe the biochemical and structural characterization of CyaB from $P$. aeruginosa. We determined that the MASE2 domain is required for significant catalytic activity in vivo and anchors the catalytic domain to the cytoplasmic membrane. We identified $\mathrm{CyaB}$ residues involved in the regulation of $\mathrm{AC}$ activity using a random mutagenesis strategy and gain-of-function screen, and solved the crystal structure of the $\mathrm{CyaB}$ catalytic domain to analyze the location and function of these residues. We further describe the modulation of $\mathrm{CyaB}$ through $\mathrm{CO}_{2} / \mathrm{HCO}_{3}{ }^{-}$and known $\mathrm{AC}$ inhibitors. Our results are a first step toward understanding the physiological regulation of $\mathrm{CyaB}$ and to exploit it as a drug target.

\section{RESULTS}

\section{The CyaB N-terminal region controls catalytic activity}

$P$. aeruginosa CyaB (UniProt Q9HZ23) regulates virulence factor expression and has been implicated in coupling this process to environmental signals ${ }^{12}$. Importantly, a $P$. aeruginosa $c y a B$ mutant is attenuated in a mouse pneumonia model ${ }^{11}$. Because these observations suggest that the enzyme may serve as a drug target, we set out to study its physiological and pharmacological regulation. We previously showed that the C-terminal $\mathrm{AC}$ homology region of $\mathrm{CyaB}$ has catalytic activity in vitro ${ }^{12}$; we now explored whether regions outside the catalytic domain play a role in $\mathrm{CyaB}$ activation. We investigated how $\mathrm{AC}$ activity is affected by i) the extreme $\mathrm{N}$-terminal segment, which is basic, proline-rich, and predicted to be cytoplasmically exposed and ii) the putative MASE2 sensing domain, which contains multiple transmembrane segments (Figure 1a). We constructed cyaB alleles in which nucleotides corresponding to the first 17 amino acids $\left(c y a B_{\Delta 1-17}\right)$ or the MASE2 domain $\left(c y a B_{\Delta 1-216}\right)$ were deleted. The mutant $c y a B$ alleles encoding $\mathrm{CyaB}_{\Delta 1-17}$ and $\mathrm{CyaB}_{\Delta 1-216}$ were expressed from plasmids under the control of the IPTG-inducible tac promoter.

We assessed catalytic activity using a cAMP-dependent reporter gene (lacP1 $\Delta$ lacI-lacZ) based on the Escherichia coli lacP1 promoter, which was previously shown to reflect intracellular cAMP levels in P. aeruginosa ${ }^{30}$. Plasmid-borne $c y a B$ alleles were transferred to $P$. aeruginosa strain PAK lacking both chromosomally encoded adenylyl cyclases ( $c y a A$ and $c y a B$ ) and harboring the lac $\mathrm{P} 1 \Delta$ lacI-lacZ reporter in the vacant $\varphi$ CTX phage integration site on the chromosome. We determined the induction conditions (IPTG concentration) under which the plasmid-encoded $\mathrm{CyaB}$ proteins (wild-type and truncated forms) were expressed at levels roughly equivalent to native $\mathrm{CyaB}$ in the wild-type strain as assessed by immunoblotting bacterial lysates with anti-CyaB antibody generated against a synthetic peptide corresponding to the extreme C-terminal portion of CyaB (Figure 1b). We then assessed cAMP reporter activity under these conditions, correcting for minor differences in protein levels based on quantitative analysis of $\mathrm{CyaB}$ immunoblots (Figure 1c). Wild-type 
$\mathrm{CyaB}$, but not $\mathrm{CyaB}_{\Delta 1-17}$ or $\mathrm{CyaB}_{\Delta 1-216}$, restored wild-type reporter activity in PAKcyaAB::lacP1 $\triangle$ lacI-lacZ, with $\mathrm{CyaB}_{\Delta 1-216}$ displaying a more dramatic reduction in reporter activity than $\mathrm{CyaB}_{\Delta 1-17}$. These results indicate that both the truncated proteins have reduced activity relative to full-length $\mathrm{CyaB}$. This finding, combined with the observation that the $\mathrm{CyaB}$ catalytic domain has activity in vitro ${ }^{12}$, suggests that the CyaB catalytic domain retains function but that the $\mathrm{N}$-terminal non-catalytic domain is required for full activity in vivo. Overall, our results indicate that both the putative cytoplasmically exposed $\mathrm{N}$-terminal segment and the MASE2 domain influence CyaB AC activity in vivo.

Because $\mathrm{CyaB}$ is predicted to be an integral cytoplasmic membrane protein, we explored the possibility that $\mathrm{CyaB}_{\Delta 1-17}$ and/or $\mathrm{CyaB}_{\Delta 1-216}$ are less active in vivo due to altered subcellular localization. To determine the localization of $\mathrm{CyaB}, \mathrm{CyaB}_{\Delta 1-17}$, and $\mathrm{CyaB}_{\Delta 1-216}$ within $P$. aeruginosa, we prepared fractions containing soluble (periplasmic and cytoplasmic) and insoluble (total membrane) proteins from PAK expressing the corresponding proteins. We then separated the total membrane fraction into inner and outer membrane fractions by sarkosyl solubilization. An equivalent amount of each fraction was analyzed by immunoblotting to detect $\mathrm{CyaB}$, the cytoplasmic RNA polymerase (RNAP) beta subunit ${ }^{31}$, the inner membrane protein $\mathrm{Sec} Y$, or the outer membrane protein $\mathrm{OprF}^{32}$. Full-length $\mathrm{CyaB}$ and $\mathrm{CyaB}_{\Delta 1-17}$ were detected exclusively in the total membrane and inner membrane fractions, whereas $\mathrm{CyaB}_{\Delta 1-216}$ was present only in the soluble cytoplasmperiplasm fraction (Figure 2). These results demonstrate that $\mathrm{CyaB}$ is localized to the inner membrane of $P$. aeruginosa and that localization is MASE2-dependent. In addition, the fact that $\mathrm{CyaB}$ and $\mathrm{CyaB}_{\Delta 1-17}$ showed no difference in subcellular localization suggests that the reduced activity of $\mathrm{CyaB}_{\Delta 1-17}$ is not due to improper targeting. Taken together, these results reveal that both the extreme $\mathrm{N}$-terminal segment and the putative MASE2 sensing domain influence CyaB activity; the MASE2 domain functions in proper subcellular targeting, and the $\mathrm{N}$-terminal segment contributes in an as yet undefined way. It remains to be shown whether these effect on $\mathrm{CyaB}$ activity are static or whether they contribute to physiological $\mathrm{CyaB}$ regulation mechanisms.

\section{Identification of CyaB residues involved in enzyme activation}

We next sought to identify $\mathrm{CyaB}$ residues critical for catalytic activation. We conducted a screen for CyaB mutants with elevated activity using the lac $\mathrm{P} 1 \Delta$ lacI-lacZ reporter for cAMP production. To enhance differences between the parent strain and mutants with elevated CyaB activity, we performed the screen in a strain lacking PilG, a Chp chemosensing system component that activates $\mathrm{CyaB}^{12}$. Plasmid-based expression of wild-type levels of $\mathrm{CyaB}$ in a cyaABpilG mutant does not complement reporter activity ${ }^{12}$, leading to colonies that are less blue on X-gal plates (data not shown). To identify cyaB mutations resulting in elevated $A C$ activity, we screened for suppressors of this pilG phenotype. We generated a library of random substitution mutations in plasmid-borne cyaB (pMMBV2-cyaB) by PCR mutagenesis and screened it in PAKcyaABpilG on X-gal plates under conditions that yielded wild-type $\mathrm{CyaB}$ levels. To identify the $c y a B$ lesions, we transferred the pMMBV2-cyaB plasmids from darker colonies to $E$. coli $\mathrm{DH} 5 \alpha$, isolated plasmid DNA and sequenced cyaB. We identified $28 \mathrm{cyaB}$ clones harboring single missense mutations representing 10 unique sites within CyaB (Table I): two in the linker region, six in the catalytic domain and two in the C-terminal tail (Figure 3a). We then transferred a representative clone harboring each unique mutation into PAKcyaAB to assess cAMP reporter activity. Due to saturation effects, the lac $\mathrm{P} 1 \Delta$ lacI-lacZ reporter does not accurately reflect cAMP concentrations above wildtype level ${ }^{12 ; 30}$. Therefore, we assayed the $\mathrm{CyaB}$ mutants in low salt media ( $5 \mathrm{mM}$ versus $200 \mathrm{mM} \mathrm{NaCl}$ ), a condition that results in reduced intracellular cAMP accumulation ${ }^{33}$. To determine the effect of salt concentration on reporter activity, we assayed PAK::lacP1 $\Delta$ lacIlacZ in LB medium containing $5 \mathrm{mM}$ or $200 \mathrm{mM} \mathrm{NaCl}$ and observed that reporter activity 
under high-salt medium is about 2.3-fold higher than in low-salt medium (Supplementary Figure S1). We then assayed cAMP reporter activity of the CyaB mutants expressed in $\mathrm{PAK} c y a A B:: l a c \mathrm{P} 1 \Delta l a c I-l a c Z$ under low-salt conditions. Although the strains were expressed under identical induction conditions (50 $\mu \mathrm{M}$ IPTG), we examined CyaB levels by quantitative immunoblot to address the possibility that the point mutations altered protein stability. CyaB mutant protein levels were roughly comparable to that of wild-type CyaB and to adjust for the subtle differences observed, we normalized reporter activity to CyaB levels. The majority of $\mathrm{CyaB}$ mutants had significantly elevated cAMP reporter activity (greater than fourfold) compared to that of wild-type CyaB expressed in the cyaAB mutant $(P \leq 0.043)$ (Figure $3 \mathrm{~b})$. The activity of the R412H mutant was also elevated, but the increase was not statistically significant. We also transferred a $c y a B$ wild-type plasmid from the $c y a A B p i l G$ screening strain to PAKcyaAB, yielding equivalent activity to PAKcyaAB expressing pMMBV2-cyaB. We thus conclude that the increased activity displayed by the mutants is due to its nucleotide substitution in $c y a B$ and the resulting change of a CyaB protein residue, suggesting that enzyme activation is controlled by specific regions both within and outside of the catalytic domain.

\section{Crystal structure of the CyaB catalytic domain}

In order to interpret data on the physiological (see above) and pharmacological (see below) regulation of $\mathrm{CyaB}$, we solved the crystal structure of the $P$. aeruginos CyaB catalytic domain. The enzymatically active $\mathrm{CyaB}$ catalytic core, comprised of residues 220-416 $\left(\mathrm{CyaB}_{220-416}\right)$, was produced in $E$. coli and the homodimeric $\mathrm{CyaB}$ protein obtained from purification was crystallized. The $\mathrm{CyaB}$ structure was then solved using Patterson search techniques with the AC homodimer of CyaC from Spirulina platensis 16 as a search model, and it was refined at $1.5 \AA$ resolution to $R_{\text {cryst }}$ and $R_{\text {free }}$ values of $18.6 \%$ and $23.0 \%$, respectively (Table II). The final CyaB model comprises residues $222-416$ of two monomers, $\mathrm{A}$ and $\mathrm{B}$, in the asymmetric unit, with no residues in the disallowed region of the Ramachandran plot and $99 \%$ of the residues in the most favourable areas.

The overall structure of $\mathrm{CyaB}$ (Figure 4a,b) shows, besides small deviations in detail, the general architecture of Class III AC enzymes $9 ; 17 ; 18$. Each monomer contains a central seven-stranded $\beta$-sheet, shielded from solvent by $\alpha$-helices(Figure $4 \mathrm{a}$ ). The $\beta$-strands $\beta 1$ to $\beta 4$ form a $\beta \alpha \beta \beta \alpha \beta$ arrangement, and a two-stranded $\beta$ sheet formed by $\beta 5$ and extensions of $\beta 4$ protrude from the core of the domain. This small sheet interacts with $\beta 2$ and $\beta 3$ of the partner monomer to form the wreath-like, catalytically active dimer (Figure $4 \mathrm{~b}$ ). Two active sites are formed at the dimer interface, employing substrate binding and catalytic residues from both monomers (Figure 4c).

CyaB more closely resembles the "closed" conformation of $\mathrm{CyaC}$, which presumably approximates a product complex, as opposed to the "open" conformation likely representing the apo form before substrate binding (Figure $4 \mathrm{~d}$ ) ${ }^{16}$. Thus, we expect the observed CyaB conformation needs to open up to allow entry of the substrate, which would explain why no substrate analog was visible in the active site after soaking experiments (data not shown). Substrate analog cocrystallization attempts also resulted in apoenzyme crystals, which could indicate that the observed, closed $\mathrm{CyaB}$ conformation crystallizes preferentially.

Comparison of the $\mathrm{CyaB}$ active site with the two CyaC conformations reveals that all residues important for substrate binding and catalysis are in similar positions; however, several showed substantial differences in their conformation. In particular, one of the two conserved Asp residues responsible for binding the divalent metal ions, which in turn bind to the substrate phosphates, is turned away from the ion positions (Asp234; Figure 4e). In contrast to the active site entrance, this state appears like an open state, ready to accommodate the metal ions, similar to one of two sites in the Class III GC Cya2 ${ }^{18}$. Similar to Cya2, the catalytic dimer shows asymmetry, which might indicate that both active sites 
are in different states. This observation could even hint at half-of-the-sites activity, i.e. one active site being in a catalytically active state is coupled to the second one being in an inactive conformation, which was previously observed for other Class III cyclases ${ }^{18 ;} 34$.

\section{Structural implications for CyaB activation}

The residues implicated in $\mathrm{CyaB}$ activation are highlighted in the crystal structure of the $\mathrm{CyaB}$ catalytic domain in Figure 5a,b. The $\mathrm{N}$ - and $\mathrm{C}$-terminal extensions of the CyaB core crystallized here show similarities to corresponding regions in other AC enzymes, but they have not been functionally or structurally characterized and were therefore omitted from our analysis. It should be noted, however, that the activating mutations in C-terminus and linker might indicate regulatory functions for these regions (although static effects cannot be excluded - see above) and the MASE2 domain connected to the linker.

The most $\mathrm{N}$-terminal activating mutation identified in the genetic screen (above), Arg318Trp, affects a residue in the C-terminus of $\alpha 3$ on the surface of the catalytic core, oriented toward the solvent (Figure 5a,b). Interestingly, the corresponding region of the mammalian transmembrane ACs (tmACs) serves as a binding site for the regulatory heterotrimeric G-protein subunit $\mathrm{G}_{\mathrm{s}} \alpha^{15}$, and most likely $\mathrm{G}_{\mathrm{i}} \alpha^{35}$. Binding of G-protein subunits is predicted to regulate tmAC activity by influencing the relative orientation of the catalytic domains. The activating effect of changing Arg to a large, hydrophobic Trp might indicate that within the full-length $\mathrm{CyaB}$ protein, this area is shielded from solvent and thus also contributes to a regulatory interaction interface. However, the C-terminus of helix $\alpha 3$ and the connected loop show significant variations in length and sequence between the sAClike and tmAC families ${ }^{9}$, and Arg318 is not conserved in other sAC-like ACs. Therefore, Arg318 may mediate regulation by a CyaB-specific partner domain that is either part of fulllength CyaB (e.g., the MASE2 domain) or a separate regulatory protein. Interfering with this regulatory interaction may be an attractive approach for drug development. It is tempting to speculate that this protein region generally plays a role in adapting individual Class III ACs to their specific regulators.

Several of the identified activating mutations affect positions involved in interactions with two structural elements that undergo major conformational changes during the catalytic cycle, the $\alpha 1$ helix and the $\beta 7 / \beta 8$ loop ${ }^{9}$. The mutations Leu326Pro (Figure 5a) and Phe399Ile/His are also close to putative substrate binding residues (Arg329 and Lys397, respectively) and could have direct effects on the local protein conformation, but their roles in packing interactions seem more obvious explanations for the activating effects. Leu326Pro affects the hydrophobic interface formed by the N-terminus of $\beta 4$, the Arg318carrying $\alpha 3$ discussed above, and the flexible helix $\alpha 1$, which has to move toward the dimer center $9 ; 36$, either upon substrate binding ${ }^{19}$ or substrate conversion ${ }^{16}$. The mutation might make $\alpha 1$ more flexible due to less tight packing, which would facilitate active site closure or its induction through modulator binding. In contrast to Arg318Trp, which likely affects $\mathrm{CyaB}$ activity only in presence of a partner domain or protein (see above), the Leu326Pro mutation would be expected to directly increase specific activity of the isolated catalytic domain. We therefore generated this single site variant, $\mathrm{CyaB}_{220-416}$-Leu326Pro, and compared its specific activity to wildtype $\mathrm{CyaB}_{220-416}$. Consistent with the proposed facilitating effect on the catalytic $\beta 7 / \beta 8$ movement, the Leu326Pro mutation indeed increased specific activity due to significantly faster substrate turnover, whereas the substrate affinity was comparable to wildtype $\mathrm{CyaB}_{220-416}$ (Figure 5b). Similarly to Leu326, residue Phe399, which was substituted with either His or Ile, resides in the $\beta 7 / \beta 8$-loop that moves, together with $\alpha 1$, during catalysis, thereby repositioning the phosphate-binding residue Lys380. Exchange of the phenylalanine to a smaller (Ile) or less hydrophobic (His) residue should weaken the packing of this loop against $\alpha 4$ and thereby make it easier for the loop to move. The Glu377Gly mutation in $\alpha 5$ appears mainly solvent exposed in the closed 
conformation seen in the $\mathrm{CyaB}$ structure, but it might contribute to interactions to the $\beta 7 / \beta 8$ loop, similar to Phe399, in more open conformations. Although an increase in CyaB activity due to the Arg412His mutation did not achieve statistical significance in our analysis, the fact that this mutant was identified in our screen suggests this residue may still play a role in enzyme activation. The mutation Arg412His affects a region opposite from the active site, on the outside of the dimer and might thus influence interactions with regulatory partners (domains or proteins), but its position at the base of the $\beta 7 / \beta 8$ arm indicates that its effect might again be based on influencing the movement of $\beta 7 / \beta 8$. In contrast, the mutation Ile352Thr affects a position not contacting $\beta 7 / \beta 8$, but involved in packing $\beta 5$ and $\alpha 4$ (Figure 4a,b; Figure 5a). This residue is located next to Thr351, which recognizes the substrate base (Figure 4c) and likely needs to rearrange during transition state formation. We assume the neighbouring residue influences these rearrangements through packing interactions that modulate the backbone flexibility of this region.

While these hypothesized roles for the identified residues are consistent with our knowledge on general mechanisms of Class III catalysis and regulation, they reveal mechanistic differences from other Class III ACs, such as the one involving Arg318, suggesting that interfering with these mechanisms should yield highly specific drugs.

\section{CyaB belongs to the inorganic carbon-responsive family of sAC-like enzymes}

Based on key active site polymorphisms, $\mathrm{CyaB}$ is assigned to the Class IIIb $\mathrm{ACs}$, whose members are characterized by responsiveness to $\mathrm{CO}_{2} / \mathrm{HCO}_{3}{ }^{-9} ; 22$. To examine the response of $\mathrm{CyaB}_{217-463}$ to $\mathrm{CO}_{2} / \mathrm{HCO}_{3}{ }^{-}$, it was necessary to first determine its divalent metal ion requirement and responsiveness to $\mathrm{pH}$. $\mathrm{CyaB}_{217-463}$ activity was significantly higher in the presence of $\mathrm{Mn}^{2+}$-ATP compared to $\mathrm{Mg}^{2+}$-ATP as substrate (Figure 6; note differences in scale), as observed for most Class III ACs. In presence of either $\mathrm{Mg}^{2+}$-ATP or $\mathrm{Mn}^{2+}$-ATP, $\mathrm{CyaB}_{217-463}$ activity increased with $\mathrm{pH}$ values ranging from 6.5 to 8.5 (Figure 6a). $\mathrm{CO}_{2} /$ $\mathrm{HCO}_{3}{ }^{-}$stimulated $\mathrm{CyaB}_{217-463}$ activity in the presence of either divalent, with optimal stimulation occurring at $\mathrm{pH} 7.5$ (Figure 6a). As $\mathrm{Mn}^{2+}$ - $\mathrm{ATP}$ at $\mathrm{pH} 7.5$ supported both optimal specific activity and $\mathrm{CO}_{2} / \mathrm{HCO}_{3}{ }^{-}$dependent enzyme stimulation, further analysis was performed under these conditions. Stimulation of specific enzyme activity was cation independent (Figure 6b), and maximal stimulation occurred at $50 \mathrm{mM}$ salt (Figure 6c). We were unable to calculate an accurate $\mathrm{EC}_{50}$ because activity dropped precipitously at concentrations $>50 \mathrm{mM} \mathrm{HCO}_{3}{ }^{-}$presumably due to $\mathrm{HCO}_{3}{ }^{-}$-dependent precipitation of the essential divalent cation. However, we were able to conclude that stimulation occurs over physiologically relevant $\mathrm{CO}_{2} / \mathrm{HCO}_{3}{ }^{-}$concentrations (typically 5 to $25 \mathrm{mM}$ ). $20 \mathrm{mM} \mathrm{CO}$ / $\mathrm{HCO}_{3}{ }^{-}$increased enzyme activity compared to $\mathrm{Cl}^{-}$through an increase in enzyme turnover ( $\mathrm{k}_{\text {cat }}$ of $3.8 \pm 0.2 \mathrm{~min}^{-1}$ and $1.2 \pm 0.1 \mathrm{~min}^{-1}$, respectively [S.E.M., $\mathrm{N}=6$ ]) consistent with other Class IIIb enzymes $22 ; 37$. We thus conclude that physiological concentrations of $\mathrm{CO}_{2} /$ $\mathrm{HCO}_{3}{ }^{-}$modulate $\mathrm{CyaB}$ activity. It remains to be determined in which physiological pathways this regulatory mechanism is employed.

\section{Pharmacological inhibition of CyaB}

CyaB might serve as target for novel antibiotics, and we therefore tested a number of known Class III AC inhibitors for their efficacy against purified enzyme. Catechol derivatives of estrogen (CE) were previously shown to be non-specific, noncompetitive inhibitors of Class III ACs ${ }^{38}$. Consistently, 2-hydroxy estradiol inhibited $\mathrm{CyaB}_{220-416}$ significantly at $100 \mu \mathrm{M}$ (Figure 7a). Previous crystallographic studies revealed that the catechol in CEs chelates the catalytic divalent metal ion, and that the hydrophobic steroid scaffold binds to a pocket present in all Class III cyclases, albeit with differences in the exact shape ${ }^{38}$. An overlay of $\mathrm{CyaB}$ with the $\mathrm{CE}$ complex of $\mathrm{CyaC}$ (Figure $7 \mathrm{~b}$ ) indeed shows the presence of an analogous pocket in $\mathrm{CyaB}$. Using the $\mathrm{CyaC} / \mathrm{CE}$ structure, we developed more specific ligands, $\mathrm{BCC} 2$ 
and BCC8, which specifically and potently inhibited CyaC and mammalian sAC, but not tmACs ${ }^{29}$. In $\mathrm{CyaB}$, the $\mathrm{CE}$ binding pocket is slightly smaller, which might indicate that the bulkier compound BCC2 should not be able to bind efficiently. Indeed, $100 \mu \mathrm{M}$ BCC2 only weakly inhibited $\mathrm{CyaB}$ activity (Figure 7a). This difference in BCC2 response among the Class IIIb ACs examined indicates that exploiting the CE binding site may be an approach enabling the development of specific inhibitors for individual ACs including CyaB.

All Class IIIb cyclases tested in our laboratories have been sensitive to the inhibitor KH7, which appears to be specific for sAC-like ACs ${ }^{27}$ and whose mechanism of action is unknown. Surprisingly, the sAC-like enzyme CyaB was completely insensitive to KH7 at concentrations up to $100 \mu \mathrm{M}$. Despite this observation, we hypothesized that minor modifications of $\mathrm{KH} 7$ chemical space could yield effective inhibitors of CyaB. We therefore screened $57 \mathrm{KH} 7$-related compounds that differed with respect to the functional groups attached to the KH7 acyl hydrazone backbone (Figure 7c,d). Several compounds increased the assay signal, and we will test in a separate study whether they are indeed CyaB activators, possibly employing the mechanism of the AC activator forskolin ${ }^{9}$. However, one of these compounds, KH7.148 (Figure $7 d$ ), inhibited CyaB activity with an $\mathrm{IC}_{50}$ of $\sim 10 \mu \mathrm{M}$ (Figure 7e). Interestingly, KH7.148 was the only KH7-like compound with a catechol moiety, and this shared chemical structure could indicate a mechanism of inhibition similar to that of catechol estrogens ${ }^{38}$. The steepness of the KH7.148 inhibition curve (Figure 7e) could indicate cooperativeness compatible with binding to the CE site, which is partly formed by the $\mathrm{CE}$ molecule bound to the second site of the $\mathrm{AC}$ dimer ${ }^{38}$, but further experimental work is required to clarify the KH7.148 mechanism. Interestingly, KH7.148 is only a weak inhibitor of basal mammalian sAC activity, with an $\mathrm{IC}_{50}>100 \mu \mathrm{M}$ (Supplementary Figure S2), showing that KH7.148 is not a promiscuous inhibitor but shows selectivity even between these two closely related enzymes. These results indicate that it is possible to develop highly specific inhibitors of $\mathrm{CyaB}$, an important step in exploiting this enzyme as a therapeutic target, and that KH7.148 can serve as a first lead compound. Furthermore, the $\mathrm{CyaB}$ structure described here provides a starting point for future structurebased drug development efforts.

\section{DISCUSSION}

The nucleotidyl cyclase Class III is a large family of proteins featuring a conserved catalytic domain architecture but exhibits significant sequence variation in most residues not directly involved in catalysis $9 ; 17$. Consistently, the catalytic domains respond to different signalling molecules, such as G-proteins, calmodulin, or $\mathrm{CO}_{2} / \mathrm{HCO}_{3}{ }^{-}$. Additionally, each Class III AC catalytic domain is fused to unique regulatory domains ${ }^{14}$, providing individual regulation for specific ACs. The molecular basis for AC regulation has been characterized for a few examples ${ }^{39}$, and an emerging theme for AC regulation by different sensor domains and binding proteins is an induced relative rotation of the catalytic domains that optimizes the active site at the dimer interface ${ }^{9 ; 15}$. Our finding that the MASE2 domain of $P$. aeruginosa $\mathrm{CyaB}$ is required for membrane localization and full catalytic activity is consistent with a model in which MASE2 receives an activating signal and, in response, influences the relative rotation of the catalytic domains. Such a signaling function of MASE2 in CyaB is supported by the fact that the MASE2 domain is distinct from the membrane anchors present in other Class III ACs, but further experiments are needed to identify the factor(s) triggering MASE2. Our assessment of the regulatory regions of CyaB beyond the MASE2 domain also implicates the extreme $\mathrm{N}$-terminal (cytosol-exposed) region of $\mathrm{CyaB}$ in catalytic regulation, but it is not clear whether this regulation is direct, via contact with the catalytic domain itself, or indirect, via inducing conformational alteration of MASE2 that in turn affects catalytic activity. 
$\mathrm{CyaB}$ is required for production of multiple $P$. aeruginos $a$ virulence factors including secreted toxins and type IV pili (tfp), which are surface fibers at the bacterial pole mediating adherence to host tissue and "twitching motility", a surface-associated motility that involves rapid cycles of pilus extension and retraction. CyaB is localized in the bacterial poles ${ }^{40}$, a location shared by the tfp biogenesis machinery ${ }^{41}$ and components of the Chp chemosensory system ${ }^{40 ; 42}$. We predict that the MASE2 domain, which we show here is required for inner membrane targeting, is also likely to be required for localization to the bacterial poles. The localization pattern of $\mathrm{CyaB}$, in combination with our finding that $\mathrm{CyaB}$ catalytic activity is regulated by the Chp system ${ }^{12}$, suggests the enzyme may be involved in coupling an unknown signal to functional output (tfp extension and retraction), possibly as part of a multi-protein complex anchored at the inner membrane. The Chp system complex consists of a histidine kinase, accessory factors, and soluble receiver proteins anchored to an inner membrane receptor (MCP). One intriguing possibility is that CyaB activity is controlled via interaction with Chp system regulatory domains. In support of this model are examples of Class III AC domains coupled to two-component kinase and receiver domains ${ }^{14 ; 43}$, and the report that AC/chemotaxis MCP chimeras produce cAMP in response to the appropriate ligand ${ }^{44}$; it remains to be shown, however, whether Chp system regulation of $\mathrm{CyaB}$ is direct or indirect.

Although regulation by $\mathrm{CO}_{2} / \mathrm{HCO}_{3}{ }^{-}$is a common feature of sAC-like $\mathrm{ACs}$, this regulation has features specific for $\mathrm{CyaB}$. For this $\mathrm{AC}$, it is $\mathrm{pH}$ dependent with an optimum at 7.5 and is distinct from previous modes of regulation which were either optimal at acidic $\mathrm{pH}$, e.g. Slr $1991^{37}$, or relatively $\mathrm{pH}$ independent, e.g. sAC ${ }^{45}$. As mentioned, select fungi utilize $\mathrm{CO}_{2}$ to initiate a pathogenic response. An optimal $\mathrm{pH}$ of 7.5 for carbon regulation of $\mathrm{CyaB}$ might represent a mechanism by which the relatively high $\mathrm{CO}_{2} / \mathrm{HCO}_{3}{ }^{-}$concentration in the eukaryotic host can increase cAMP accumulation and contribute to the organism's pathogenic lifestyle.

The ACs of microbial sensor systems regulating virulence factors are interesting drug targets. In two species of pathogenic fungi, Candida albicans and C. neoformans, a $\mathrm{CO}_{2^{-}}$ sensing system based on a sAC-like AC and a carbonic anhydrase (CA) regulate virulent growth $25 ; 26 ; 46 ; 47$. Inhibition of CAs has been extensively studied, but despite some promising novel approaches such as using novel chelating groups for the CA catalytic zinc ion ${ }^{48}$, it has proven difficult to develop compounds specific for the microbial enzyme but inactive against host CAs ${ }^{26}$. The fact that $\mathrm{CyaB}$ also responds to $\mathrm{CO}_{2} / \mathrm{HCO}_{3}{ }^{-}$might indicate that a CA contributes to its regulation, but further studies will be needed to identify this or other $\mathrm{CyaB}$ regulators and the mechanisms they employ. The only option currently available to interfere with this $P$. aeruginosa system is direct inhibition of the CyaB catalytic domain. Specific inhibition of Class III ACs is challenging, but progress in recent years has stimulated efforts to exploit these proteins as drug targets $29 ; 49 ; 50$. Intriguingly, we find that the $\mathrm{CyaB}$ binding pocket for catechol estrogen and $\mathrm{BCC} 2 / 8^{29 ;} 38$ shows differences to those in other sAC-like enzymes. Thus far, these differences correlated with compound sensitivity suggesting that targeting this $\mathrm{CyaB}$ pocket is an attractive approach for developing specific drugs. Also of interest, the compound KH7, which was effective against all previously tested Class IIIb cyclases, is relatively inert towards $\mathrm{CyaB}$. In contrast, a single catechol-containing KH7-derived compound (KH7.148) proved to be a potent, selective inhibitor of CyaB, indicating that this and other $\mathrm{KH} 7$ derivatives hold the potential to be developed into therapeutic drugs that exploit CyaB's role in virulence regulation. Mechanistic studies on AC inhibition by KH7-like compounds will be an important part of the efforts to develop AC-targeted therapeutics. Such efforts focused on P. aeruginosa should be complemented by further studies on the $\mathrm{CyaB}$ regulatory mechanisms described here. 


\section{MATERIALS AND METHODS}

\section{Plasmid and strain construction}

Strains used in this study are listed in Supplementary Table S1. The cyaB alleles encoding truncated versions of $\mathrm{CyaB}\left(c y a B_{\Delta 1-17}\right.$ and $\left.c y a B_{\Delta 1-216}\right)$ for expression in $P$. aeruginosa correspond to CyaB amino acid positions $18-463$ or $217-463$, respectively (cyaB $B_{\Delta 1-17}$ includes the existing methionine codon at position 18 whereas $c y a B_{\Delta 1-216}$ has an added methionine start codon). The expression plasmids pMMBV2-cyaB $B_{\Delta 1-17}$ and pMMB$c y a B_{\Delta 1-216}$ were made by PCR amplification using chromosomal DNA from $P$. aeruginosa strain PAK as template and either $5^{\prime} \mathrm{ScyaB} / 3^{\prime} \mathrm{PA} 3217$ or 5'cyaB200/3'PA3217 oligonucleotide pairs, respectively (Supplementary Table S2). Amplified $c y a B_{\Delta 1-17}$ and $c y a B_{\Delta 1-216}$ fragments were cloned into pDONR201 by Gateway cloning (Invitrogen) and then transferred to pMMBV2GW or pMMBGW, respectively. All pMMB-derived plasmids were transferred to PAKcyaAB::lacP1 1 lacI-lacZ by triparental mating as described ${ }^{51}$.

\section{cAMP reporter assay and immunoblotting}

$\beta$-galactosidase assays were performed as previously described ${ }^{12}$ using bacteria grown in $\mathrm{LB}$ broth to mid-log growth phase $\left(\mathrm{OD}_{600}=0.8\right)$. For the indicated assays, bacteria were grown in $\mathrm{LB}$ with $5 \mathrm{mM} \mathrm{NaCl}$ (low salt) or $200 \mathrm{mM} \mathrm{NaCl}$ (high salt). For CyaB immunoblot analysis, bacteria were normalized based on $\mathrm{OD}_{600}$ reading and pelleted by centrifugation for 2 minutes at 13,000 x g. To create whole-cell lysates, bacteria were suspended in $100 \mu \mathrm{l} \mathrm{H}_{2} 0$ and treated with $1 \mu \mathrm{l} \mathrm{DNaseI}(10 \mathrm{mg} / \mathrm{ml})$ for 10 minutes at $37^{\circ} \mathrm{C}$. SDS/PAGE sample buffer $(100 \mu \mathrm{l})$ was then added followed by incubation at $45^{\circ} \mathrm{C}$ for 45 minutes. Membranes were probed with affinity-purified antiserum against CyaB (1:5,000 dilution) and visualized by enhanced chemiluminescence as described ${ }^{12}$. For quantitative analysis of immunoblot autoradiographs, the signal intensity of bands corresponding to $\mathrm{CyaB}, \mathrm{CyaB}_{\Delta 1-17}$ or $\mathrm{CyaB}_{\Delta 1-216}$ was determined by densitometry using ImageJ software (National Institutes of Health; rsbweb.nih.gov/ij/). To correct cAMP reporter activity values for $\mathrm{CyaB}$ protein levels, the signal density of each sample relative to that of the control (cyaA carrying empty vector or $c y a A B$ carrying pMMBV2-cyaB) was determined and used to calculate "relative activity" [relative activity $=\beta$-galactosidase activity (Miller units)/ [sample signal density/control signal density]]. Calculations to assess statistical significance for relative activity values were made using an unpaired two-tailed $t$-test.

\section{Bacterial fractionation}

$P$. aeruginosa strains were grown in $500 \mathrm{ml} \mathrm{LB}$ broth with the indicated amount of isopropyl- $\beta$-thiogalactoside (IPTG) at $37^{\circ} \mathrm{C}$ for $2.5 \mathrm{~h}$ and harvested by centrifugation at $10,000 \mathrm{x}$ g. Fractionation was conducted based on the protocol of Boyd and Lory ${ }^{52}$. Briefly, the pellets were resuspended in $4 \mathrm{ml}$ of $50 \mathrm{mM}$ Tris, $\mathrm{pH} 7.5,10 \mathrm{mM} \mathrm{MgCl}_{2}$ and treated with RNase I and DNase I ( $50 \mu \mathrm{g} / \mathrm{ml})$ for $10 \mathrm{~min}$. Bacteria were lysed by 2 passages through a French pressure cell $\left(8000 \mathrm{lb} / \mathrm{in}^{2}\right.$ ). Phenylmethysulfonyl fluoride (PMSF) was added to 100 $\mu \mathrm{g} / \mathrm{ml}$, lysozyme was added to $0.5 \mathrm{mg} / \mathrm{ml}$, and the solution was incubated at room temperature for $1 \mathrm{~h}$. The lysate was centrifuged at $10,000 \times \mathrm{g}$ for $10 \mathrm{~min}$ to remove unlysed cells and the resulting supernatant was centrifuged at $100,000 \times \mathrm{g}$ for $1 \mathrm{~h}$ to create total membrane (pellet) and cytosol/periplasm (supernatant) fractions. The cytosol/periplasm fraction was subjected to a second round of centrifugation at $100,000 \times \mathrm{g}$ for $1 \mathrm{~h}$. The total membrane fraction was suspended in $5 \mathrm{M}$ urea, $100 \mathrm{mM}$ Tris, $\mathrm{pH} 7.5$ by passage through a 22 -gauge needle to remove peripheral membrane proteins. The total membrane fraction was centrifuged at $100,000 \times \mathrm{g}$ for $1 \mathrm{~h}$ and then subjected to a second wash with $5 \mathrm{M}$ urea, 100 $\mathrm{mM}$ Tris, $\mathrm{pH}$ 7.5. The total membrane fraction was suspended in phosphate buffered saline (PBS). Sarkosyl was added to $0.25 \%$ and mixtures incubated on ice for $1 \mathrm{~h}$ and then centrifuged at 100,000 x g for $1 \mathrm{~h}$. The sarkosyl-soluble (inner membrane) fraction was 
subject to a second round of centrifugation at $100,000 \times \mathrm{g}$. The sarkosyl-insoluble (outer membrane) fraction was suspended in PBS plus $0.25 \%$ sarkosyl and centrifuged again at $100,000 \times \mathrm{g}$ for $1 \mathrm{~h}$. The final outer membrane fraction was suspended in PBS by passage through a 22-gauge needle, centrifuged at $13,000 \times \mathrm{g}$ for $1 \mathrm{~min}$ to pellet debris and the supernatant was transferred to a new tube. Protein concentrations for membrane and cytosol/ periplasm fractions were determined using BCA protein assay (Pierce). Samples for CyaB immunoblotting were solubilised in SDS/PAGE sample buffer at $45^{\circ} \mathrm{C}$ for 45 minutes; all other samples were solubilised at $95^{\circ} \mathrm{C}$ for 5 minutes. Samples were resolved by SDS/PAGE on $12 \%(\mathrm{CyaB})$ or $7.5 \%$ (RNA polymerase (RNAP), OprF, and SecY) acrylamide gels and transferred to nitrocellulose membranes. Immunoblots were probed with anti-CyaB antibody $(1: 5,000){ }^{12}$, antiserum specific for $\operatorname{OprF}(1: 20,000)$ or $\operatorname{Sec} Y(1: 5000)\left({ }^{32}\right.$; gift of George O'Toole), or antibody against E. coli RNAP $\beta$ subunit (1:10,000; Neoclone). CyaB, OprF and $\mathrm{Sec} Y$ were detected with horseradish peroxidase (HRP)-conjugated goat anti-rabbit Ig (Jackson; 1:25,000); RNAP was detected with HRP-conjugated goat anti-mouse Ig (Jackson; 1:25,000). Immunoblots were developed using enhanced chemiluminescence reagents (Millipore) and visualized by autoradiography.

\section{CyaB mutagenesis and screening}

PCR mutagenesis of $c y a B$ was performed using Taq DNA polymerase (Qiagen), ATTB1 $1^{\text {start }}$ and ATTB2 $2^{\text {stop }}$ oligonucleotides ${ }^{7}, 0.5 \mu \mathrm{M} \mathrm{MgCl}_{2}$ and pMMBV2-cyaB as template. The pool of amplified products were cloned into $\mathrm{pMMBV}^{12}$ by Gateway cloning (Invitrogen) and transformed into E. coli DH5 $\alpha$. The plasmid library carrying mutagenized cyaB was transferred to PAKcyaABpilG::lacP1 1 lacI-lacZ by triparental mating. Dilutions of the bacteria were plated on LB agar plates containing $25 \mu \mathrm{g} / \mathrm{ml}$ irgasan, $150 \mu \mathrm{g} / \mathrm{ml}$ carbenicillin (carb), $40 \mu \mathrm{g} / \mathrm{ml}$ (X-gal) and $50 \mu \mathrm{g} / \mathrm{ml}$ IPTG. Colonies that appeared darker blue were selected from plates containing approximately 500 colonies. Candidate plasmids were recovered from $P$. aeruginosa by suspending the bacteria in water, incubating for 10 minutes at $95^{\circ} \mathrm{C}$ followed by centrifugation for $1 \mathrm{~min}$. An aliquot of the resulting supernatant was transformed into E. coli DH5 $\alpha$, selecting on plates containing $30 \mu \mathrm{g} / \mathrm{ml}$ carb. pMMBV2$c y a B$ mutant plasmids were harvested from $E$. coli $\mathrm{DH} 5 \alpha$ for sequencing and then transferred by triparental mating to PAKcyaAB::lacP1 1 lacI-lacZ.

The $\mathrm{CyaB}_{220-416}$ mutant Leu326Pro was generated from the $\mathrm{CyaB}_{220-416}$ wildtype expression construct (see below) using the QuickChange Lightning kit (Agilent), and the protein was expressed and purified as described for wildtype $\mathrm{CyaB}_{220-416}$ (see below).

\section{Recombinant protein production and purification}

Open reading frames corresponding to the catalytic domain of CyaB from P. aeruginosa strain PAK, with or without the C-terminal tail (residues 220-416 and 217-463 for $\mathrm{CyaB}_{220-416}$ and $\mathrm{CyaB}_{217-463}$, respectively), were cloned into pQE30 (Qiagen), resulting in an N-terminal His-tag with $\left(\mathrm{CyaB}_{220-416}\right)$ or without $\left(\mathrm{CyaB}_{217-463}\right)$ a TEV protease cleavage site. Constructs were expressed in E. coli SG13009[pREP4] and M15[pREP4] (Qiagen) in Luria-Bertani broth containing $100 \mu \mathrm{g} / \mathrm{ml}$ ampicillin and $50 \mu \mathrm{g} / \mathrm{ml} \mathrm{kanamycin}$ for $18 \mathrm{~h}$ at $20^{\circ} \mathrm{C}$ after induction with $0.5 \mathrm{mM}$ IPTG at an $\mathrm{OD}_{600}$ of 0.6 . Harvested cells were resuspended in $50 \mathrm{mM}$ Tris- $\mathrm{HCl}$, pH 7, $200 \mathrm{mM} \mathrm{NaCl}, 3 \mathrm{mM}$ DTT, $0.25 \mathrm{mM}$ PMSF, treated with $0.2 \mathrm{mg} / \mathrm{ml}$ lysozyme for $15 \mathrm{~min}$ on ice, and disrupted in a French Press. Cleared lysate (50 min centrifugation at 50,000 $\mathrm{xg}$ and $4^{\circ} \mathrm{C}$ ) was supplemented with $5 \mathrm{mM}$ imidazole and allowed to bind to Ni-NTA agarose (Qiagen) for $1 \mathrm{~h}$ at $4^{\circ} \mathrm{C}$. The resin was washed with 10 volumes of $50 \mathrm{mM}$ Tris- $\mathrm{HCl}, \mathrm{pH}$ 7, $400 \mathrm{mM} \mathrm{NaCl}, 10 \mathrm{mM}$ imidazole, $2 \mathrm{mM}$ DTT, and

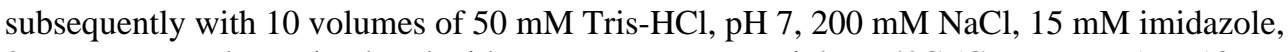
$2 \mathrm{mM}$ DTT, and protein eluted with TEV protease overnight at $4^{\circ} \mathrm{C}\left(\mathrm{CyaB}_{220-416}\right)$ or 10 volumes of $50 \mathrm{mM}$ Tris- $\mathrm{HCl}, \mathrm{pH}$ 7, $200 \mathrm{mM} \mathrm{NaCl}, 150 \mathrm{mM}$ imidazole, $2 \mathrm{mM}$ DTT 
$\left(\mathrm{CyaB}_{217-463}\right)$. Cleaved $\mathrm{CyaB}_{220-416}$ protein was eluted in $50 \mathrm{mM}$ Tris-HCl, $\mathrm{pH}$ 7, $150 \mathrm{mM}$ $\mathrm{NaCl}, 2 \mathrm{mM}$ DTT and concentrated in a $10 \mathrm{kDa}$ Amicon concentrator (Millipore). For crystallography, $\mathrm{CyaB}_{220-416}$ was subjected to size-exclusion chromatography in $20 \mathrm{mM}$ Tris-HCl, pH 7, $100 \mathrm{mM} \mathrm{NaCl}, 2 \mathrm{mM}$ DTT on a Superose-12 column. Pure fractions were pooled, concentrated, frozen in aliquots in liquid nitrogen, and stored at $80^{\circ} \mathrm{C}$. Slr 1991 residues $120-337$ were expressed and purified as previously described ${ }^{37}$.

\section{Activity assays}

Regular AC assays were done in a $30 \mu \mathrm{l}$ volume of $20 \mathrm{mM}$ Tris-HCl, $\mathrm{pH}$ 7, $100 \mathrm{mM} \mathrm{NaCl}, 5$ $\mathrm{mM}$ ATP, $10 \mathrm{mM} \mathrm{MgCl} 2$, and 0.5-2.25 $\mu \mathrm{g}$ purified CyaB protein. Samples were incubated at $30^{\circ} \mathrm{C}$ for $30 \mathrm{~min}$, and cAMP concentrations determined by using an ELISA (Biomol) according to the manufacturers' instructions. Experiments were done in duplicates and results shown are representatives of at least three repetitions. AC assays to assess the response to $\mathrm{CO}_{2} / \mathrm{HCO}_{3}{ }^{-}$were performed as previously described ${ }^{45}$. Deviations from this setup are noted in the description of the respective results.

\section{Crystallization, data collection and structure solution}

For crystallization of $\mathrm{CyaB}_{220-416}$, drops were mixed from $0.8 \mu \mathrm{l}$ protein $(10 \mathrm{mg} / \mathrm{ml})$ and 0.8 $\mu \mathrm{l}$ reservoir (0.1 M MES, pH 6.5 and $12 \%$ w/v PEG 20,000), equilibrated against $0.4 \mathrm{ml}$ reservoir at $20^{\circ} \mathrm{C}$. Crystals were transferred to cryo-protection solution containing reservoir components plus $25 \%$ glycerol. A complete diffraction data set of a CyaB220-416 crystal of space group P2 was collected at $100 \mathrm{~K}$ at Swiss Light Source beamline X10SA. Indexing, scaling, and merging were done with XDS ${ }^{53}$. The structure of $\mathrm{CyaB}_{220-416}$ was solved by using Patterson search techniques with PHASER ${ }^{54}$, using the AC CyaC homodimer ${ }^{38}$ (PDB ID 1WC1) as search model. For completing the model, manual model building in Coot ${ }^{55}$ was alternated with positional and individual B-factor refinement with REFMAC ${ }^{56}$. Close to convergence of the refinement, solvent atoms and a glycerol molecule were included. The refined structure was analyzed by using Coot and ProCheck ${ }^{57}$, and structural figures were generated with PyMOL (www.pymol.org) if not stated otherwise.

\section{Supplementary Material}

Refer to Web version on PubMed Central for supplementary material.

\section{Acknowledgments}

We thank Dr. Christine Schlicker, our colleagues from the Max Planck Institute for Molecular Physiology (Dortmund, Germany), and the beamline staff of X10SA at the Swiss Light Source, Villigen, Switzerland, for technical help. This work was supported by grant ST1701/7 of Deutsche Forschungsgemeinschaft (to CSt), grant AI069116 from the National Institutes of Health (to MCW), and grants from the Leverhulme Trust and Wellcome Trust (to MJC).

\section{Abbreviations used}

$\begin{array}{ll}\text { AC } & \text { adenylyl cyclase } \\ \text { CAMP } & \text { cyclic adenosine } 3^{\prime}, 5^{\prime} \text {-monophosphate } \\ \text { GC } & \text { guanylyl cyclase } \\ \text { MASE2 } & \text { membrane associated sensor 2 } \\ \text { RNAP } & \text { RNA polymerase } \\ \text { tmAC } & \text { transmembrane AC }\end{array}$




\section{References}

1. Garau J, Gomez L. Pseudomonas aeruginosa pneumonia. Curr Opin Infect Dis. 2003; 16:135-43. [PubMed: 12734446]

2. Brennan AL, Geddes DM. Cystic fibrosis. Curr Opin Infect Dis. 2002; 15:175-82. [PubMed: 11964920]

3. Strateva T, Yordanov D. Pseudomonas aeruginosa - a phenomenon of bacterial resistance. J Med Microbiol. 2009; 58:1133-48. [PubMed: 19528173]

4. Gales AC, Jones RN, Turnidge J, Rennie R, Ramphal R. Characterization of Pseudomonas aeruginosa isolates: occurrence rates, antimicrobial susceptibility patterns, and molecular typing in the global SENTRY Antimicrobial Surveillance Program, 1997-1999. Clin Infect Dis. 2001; 32(Suppl 2):S146-55. [PubMed: 11320454]

5. West SE, Sample AK, Runyen-Janecky LJ. The $v f r$ gene product, required for Pseudomonas aeruginosa exotoxin A and protease production, belongs to the cyclic AMP receptor protein family. J Bacteriol. 1994; 176:7532-42. [PubMed: 8002577]

6. Beatson SA, Whitchurch CB, Sargent JL, Levesque RC, Mattick JS. Differential regulation of twitching motility and elastase production by Vfr in Pseudomonas aeruginosa. J Bacteriol. 2002; 184:3605-13. [PubMed: 12057955]

7. Wolfgang MC, Lee VT, Gilmore ME, Lory S. Coordinate regulation of bacterial virulence genes by a novel adenylate cyclase-dependent signaling pathway. Dev Cell. 2003; 4:253-63. [PubMed: 12586068]

8. Barzu O, Danchin A. Adenylyl cyclases: a heterogeneous class of ATP-utilizing enzymes. Prog Nucleic Acid Res Mol Biol. 1994; 49:241-83. [PubMed: 7863008]

9. Kamenetsky M, Middelhaufe S, Bank EM, Levin LR, Buck J, Steegborn C. Molecular details of cAMP generation in mammalian cells: a tale of two systems. J Mol Biol. 2006; 362:623-39. [PubMed: 16934836]

10. Yahr TL, Vallis AJ, Hancock MK, Barbieri JT, Frank DW. ExoY, an adenylate cyclase secreted by the Pseudomonas aeruginosa type III system. Proc Natl Acad Sci U S A. 1998; 95:13899-904. [PubMed: 9811898]

11. Smith RS, Wolfgang MC, Lory S. An adenylate cyclase-controlled signaling network regulates Pseudomonas aeruginosa virulence in a mouse model of acute pneumonia. Infect Immun. 2004; 72:1677-84. [PubMed: 14977975]

12. Fulcher NB, Holliday PM, Klem E, Cann MJ, Wolfgang MC. The Pseudomonas aeruginosa Chp chemosensory system regulates intracellular cAMP levels by modulating adenylate cyclase activity. Mol Microbiol. 2010; 76:889-904. [PubMed: 20345659]

13. Linder JU, Schultz JE. The class III adenylyl cyclases: multi-purpose signalling modules. Cell Signal. 2003; 15:1081-9. [PubMed: 14575863]

14. Shenroy AR, Visweswariah SS. Class III nucleotide cyclases in bacteria and archaebacteria: lineage-specific expansion of adenylyl cyclases and a dearth of guanylyl cyclases. FEBS Lett. 2004; 561:11-21. [PubMed: 15043055]

15. Tesmer JJ, Sunahara RK, Gilman AG, Sprang SR. Crystal structure of the catalytic domains of adenylyl cyclase in a complex with Gsalpha. GTPgammaS. Science. 1997; 278:1907-16. [PubMed: 9417641]

16. Steegborn C, Litvin TN, Levin LR, Buck J, Wu H. Bicarbonate activation of adenylyl cyclase via promotion of catalytic active site closure and metal recruitment. Nat Struct Mol Biol. 2005; 12:327. [PubMed: 15619637]

17. Sinha SC, Sprang SR. Structures, mechanism, regulation and evolution of class III nucleotidyl cyclases. Rev Physiol Biochem Pharmacol. 2006; 157:105-40. [PubMed: 17236651]

18. Rauch A, Leipelt M, Russwurm M, Steegborn C. Crystal structure of the guanylyl cyclase Cya2. Proc Natl Acad Sci U S A. 2008; 105:15720-5. [PubMed: 18840690]

19. Tesmer JJ, Sunahara RK, Johnson RA, Gosselin G, Gilman AG, Sprang SR. Two-metal-Ion catalysis in adenylyl cyclase. Science. 1999; 285:756-60. [PubMed: 10427002]

20. Linder JU. Substrate selection by class III adenylyl cyclases and guanylyl cyclases. IUBMB Life. 2005; 57:797-803. [PubMed: 16393782] 
21. Chen Y, Cann MJ, Litvin TN, Iourgenko V, Sinclair ML, Levin LR, Buck J. Soluble adenylyl cyclase as an evolutionarily conserved bicarbonate sensor. Science. 2000; 289:625-8. [PubMed: 10915626]

22. Cann MJ, Hammer A, Zhou J, Kanacher T. A defined subset of adenylyl cyclases is regulated by bicarbonate ion. J Biol Chem. 2003; 278:35033-8. [PubMed: 12829712]

23. Sunahara RK, Dessauer CW, Gilman AG. Complexity and diversity of mammalian adenylyl cyclases. Annu Rev Pharmacol Toxicol. 1996; 36:461-80. [PubMed: 8725398]

24. Nikolskaya AN, Mulkidjanian AY, Beech IB, Galperin MY. MASE1 and MASE2: two novel integral membrane sensory domains. J Mol Microbiol Biotechnol. 2003; 5:11-6. [PubMed: 12673057]

25. Hall RA, De Sordi L, Maccallum DM, Topal H, Eaton R, Bloor JW, Robinson GK, Levin LR, Buck J, Wang Y, Gow NA, Steegborn C, Muhlschlegel FA. CO(2) acts as a signalling molecule in populations of the fungal pathogen Candidaalbicans. PLoS Pathog. 2010; 6:e1001193. [PubMed: 21124988]

26. Schlicker C, Hall RA, Vullo D, Middelhaufe S, Gertz M, Supuran CT, Muhlschlegel FA, Steegborn C. Structure and inhibition of the $\mathrm{CO}_{2}$-sensing carbonic anhydrase Can 2 from the pathogenic fungus Cryptococcus neoformans. J Mol Biol. 2009; 385:1207-20. [PubMed: 19071134]

27. Hess KC, Jones BH, Marquez B, Chen Y, Ord TS, Kamenetsky M, Miyamoto C, Zippin JH, Kopf GS, Suarez SS, Levin LR, Williams CJ, Buck J, Moss SB. The "soluble" adenylyl cyclase in sperm mediates multiple signaling events required for fertilization. Dev Cell. 2005; 9:249-59. [PubMed: 16054031]

28. Dessauer CW, Tesmer JJ, Sprang SR, Gilman AG. The interactions of adenylate cyclases with Psite inhibitors. Trends Pharmacol Sci. 1999; 20:205-10. [PubMed: 10354616]

29. Schlicker C, Rauch A, Hess KC, Kachholz B, Levin LR, Buck J, Steegborn C. Structure-based development of novel adenylyl cyclase inhibitors. J Med Chem. 2008; 51:4456-64. [PubMed: 18630896]

30. Fuchs EL, Brutinel ED, Jones AK, Fulcher NB, Urbanowski ML, Yahr TL, Wolfgang MC. The Pseudomonas aeruginosa $\mathrm{Vfr}$ regulator controls global virulence factor expression through cyclic AMP-dependent and -independent mechanisms. J Bacteriol. 2010; 192:3553-64. [PubMed: 20494996]

31. Mougous JD, Gifford CA, Ramsdell TL, Mekalanos JJ. Threonine phosphorylation posttranslationally regulates protein secretion in Pseudomonas aeruginosa. Nat Cell Biol. 2007; 9:797-803. [PubMed: 17558395]

32. Kuchma SL, Ballok AE, Merritt JH, Hammond JH, Lu W, Rabinowitz JD, O’Toole GA. Cyclic-diGMP-mediated repression of swarming motility by Pseudomonas aeruginosa: the pilY1 gene and its impact on surface-associated behaviors. J Bacteriol. 2010; 192:2950-64. [PubMed: 20233936]

33. Rietsch A, Mekalanos JJ. Metabolic regulation of type III secretion gene expression in Pseudomonas aeruginosa. Mol Microbiol. 2006; 59:807-20. [PubMed: 16420353]

34. Sinha SC, Wetterer M, Sprang SR, Schultz JE, Linder JU. Origin of asymmetry in adenylyl cyclases: structures of Mycobacterium tuberculosis Rv1900c. Embo J. 2005; 24:663-73. [PubMed: 15678099]

35. Dessauer CW, Tesmer JJ, Sprang SR, Gilman AG. Identification of a Gialpha binding site on type V adenylyl cyclase. J Biol Chem. 1998; 273:25831-9. [PubMed: 9748257]

36. Mou TC, Masada N, Cooper DM, Sprang SR. Structural basis for inhibition of mammalian adenylyl cyclase by calcium. Biochemistry. 2009; 48:3387-97. [PubMed: 19243146]

37. Hammer A, Hodgson DR, Cann MJ. Regulation of prokaryotic adenylyl cyclases by $\mathrm{CO}_{2}$. Biochem J. 2006; 396:215-8. [PubMed: 16573521]

38. Steegborn C, Litvin TN, Hess KC, Capper AB, Taussig R, Buck J, Levin LR, Wu H. A novel mechanism for adenylyl cyclase inhibition from the crystal structure of its complex with catechol estrogen. J Biol Chem. 2005; 280:31754-9. [PubMed: 16002394]

39. Linder JU, Schultz JE. Versatility of signal transduction encoded in dimeric adenylyl cyclases. Curr Opin Struct Biol. 2008; 18:667-72. [PubMed: 19054664] 
40. Inclan YF, Huseby MJ, Engel JN. FimL regulates cAMP synthesis in Pseudomonas aeruginosa. PLoS One. 2011; 6:e15867. [PubMed: 21264306]

41. Chiang P, Habash M, Burrows LL. Disparate subcellular localization patterns of Pseudomonas aeruginosa Type IV pilus ATPases involved in twitching motility. J Bacteriol. 2005; 187:829-39. [PubMed: 15659660]

42. DeLange PA, Collins TL, Pierce GE, Robinson JB. PilJ localizes to cell poles and is required for type IV pilus extension in Pseudomonas aeruginosa. Curr Microbiol. 2007; 55:389-95. [PubMed: 17713814]

43. Kasahara M, Yashiro K, Sakamoto T, Ohmori M. The Spirulina platensis adenylate cyclase gene, cyaC, encodes a novel signal transduction protein. Plant Cell Physiol. 1997; 38:828-36. [PubMed: 9297847]

44. Kanchan K, Linder J, Winkler K, Hantke K, Schultz A, Schultz JE. Transmembrane signaling in chimeras of the Escherichia coli aspartate and serine chemotaxis receptors and bacterial class III adenylyl cyclases. J Biol Chem. 2010; 285:2090-9. [PubMed: 19923210]

45. Townsend PD, Holliday PM, Fenyk S, Hess KC, Gray MA, Hodgson DR, Cann MJ. Stimulation of mammalian G-protein-responsive adenylyl cyclases by carbon dioxide. J Biol Chem. 2009; 284:784-91. [PubMed: 19008230]

46. Mogensen EG, Janbon G, Chaloupka J, Steegborn C, Fu MS, Moyrand F, Klengel T, Pearson DS, Geeves MA, Buck J, Levin LR, Muhlschlegel FA. Cryptococcus neoformans senses $\mathrm{CO}_{2}$ through the carbonic anhydrase Can2 and the adenylyl cyclase Cac1. Eukaryot Cell. 2006; 5:103-11. [PubMed: 16400172]

47. Klengel T, Liang WJ, Chaloupka J, Ruoff C, Schroppel K, Naglik JR, Eckert SE, Mogensen EG, Haynes K, Tuite MF, Levin LR, Buck J, Muhlschlegel FA. Fungal adenylyl cyclase integrates $\mathrm{CO}_{2}$ sensing with cAMP signaling and virulence. Curr Biol. 2005; 15:2021-6. [PubMed: $16303561]$

48. Innocenti A, Muhlschlegel FA, Hall RA, Steegborn C, Scozzafava A, Supuran CT. Carbonic anhydrase inhibitors: inhibition of the beta-class enzymes from the fungal pathogens Candida albicans and Cryptococcus neoformans with simple anions. Bioorg Med Chem Lett. 2008; 18:5066-70. [PubMed: 18723348]

49. Pierre S, Eschenhagen T, Geisslinger G, Scholich K. Capturing adenylyl cyclases as potential drug targets. Nat Rev Drug Discov. 2009; 8:321-35. [PubMed: 19337273]

50. Suryanarayana S, Gottle M, Hubner M, Gille A, Mou TC, Sprang SR, Richter M, Seifert R. Differential inhibition of various adenylyl cyclase isoforms and soluble guanylyl cyclase by $2^{\prime}, 3^{\prime}$ O-(2,4,6-trinitrophenyl)-substituted nucleoside 5'-triphosphates. J Pharmacol Exp Ther. 2009; 330:687-95. [PubMed: 19494187]

51. Furste JP, Pansegrau W, Frank R, Blocker H, Scholz P, Bagdasarian M, Lanka E. Molecular cloning of the plasmid RP4 primase region in a multi-host-range tacP expression vector. Gene. 1986; 48:119-31. [PubMed: 3549457]

52. Boyd JM, Lory S. Dual function of PilS during transcriptional activation of the Pseudomonas aeruginosa pilin subunit gene. J Bacteriol. 1996; 178:831-9. [PubMed: 8550520]

53. Kabsch W. Automatic processing of rotation diffraction data from crystals of initially unknown symmetry and cell constants. J Appl Cryst. 1993; 26:795-800.

54. McCoy AJ, Grosse-Kunstleve RW, Storoni LC, Read RJ. Likelihood-enhanced fast translation functions. Acta Crystallogr D Biol Crystallogr. 2005; 61:458-64. [PubMed: 15805601]

55. Emsley P, Cowtan K. Coot: model-building tools for molecular graphics. Acta Crystallogr D Biol Crystallogr. 2004; 60:2126-32. [PubMed: 15572765]

56. Murshudov GN, Vagin AA, Dodson EJ. Refinement of macromolecular structures by the maximum-likelihood method. Acta Crystallogr D Biol Crystallogr. 1997; 53:240-55. [PubMed: 15299926]

57. Laskowski RA, Moss DS, Thornton JM. Main-chain bond lengths and bond angles in protein structures. J Mol Biol. 1993; 231:1049-67. [PubMed: 8515464] 
- Characterization of $\mathrm{CyaB}$, an adenylyl cyclase regulating $P$. aeruginosa virulence

- The MASE2 domain of CyaB acts as membrane anchor and influences cyclase activity

- Residues involved in $\mathrm{CyaB}$ regulation identified using a random mutagenesis screen

- A CyaB catalytic core crystal structure reveals location and function of the residues

- Modulation of $\mathrm{CyaB}$ through $\mathrm{CO} / \mathrm{HCO}_{3}{ }^{-}$and known $\mathrm{AC}$ inhibitors 
(a)

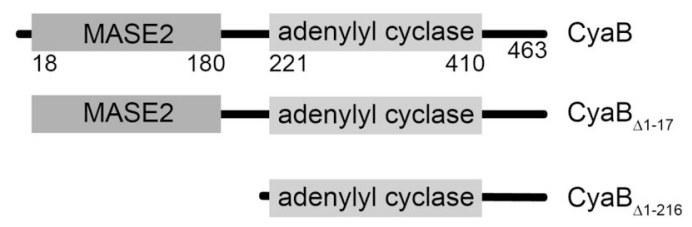

(b)

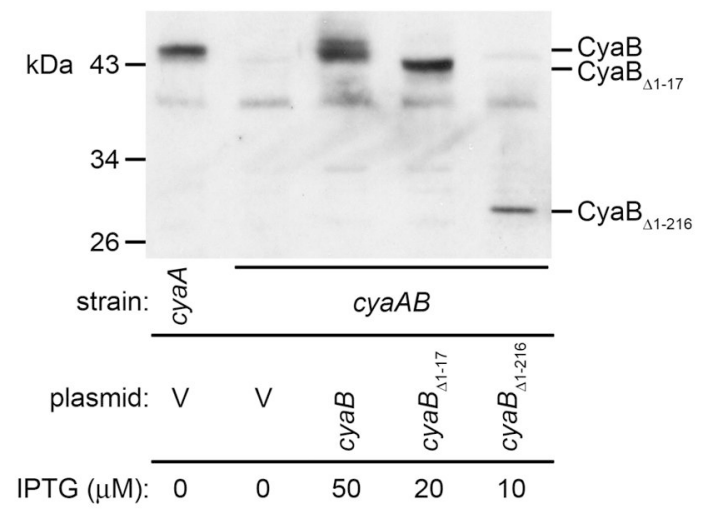

(c)

Figure 1. Regions outside the CyaB catalytic domain affect activity in vivo

(a) Diagram of the domain organization of native $\mathrm{CyaB}$ and the truncated $\mathrm{CyaB}$ proteins $\mathrm{CyaB}_{\Delta 1-17}$ and $\mathrm{CyaB}_{\Delta 1-216}$. The N-terminal MASE2 domain (PF05230) contains six predicted transmembrane $\alpha$-helices (not shown); the C-terminus contains a guanylate_cyc (PF00211) domain present in Class III GCs and ACs. Relevant amino acid positions are indicated. (b) Immunoblot of whole-cell lysates from $c y a A$ or $c y a A B$ mutants carrying either an empty vector $(\mathrm{V})$, pMMBV2 expressing $c y a B$ or $c y a B_{\Delta 1-17}$, or pMMB expressing $c y a B_{\Delta 1-216}$, probed with anti-CyaB antibody. Expression of $c y a B$ or $c y a B_{\Delta 1-17}$ from pMMBV2 at 50 or $20 \mu \mathrm{M}$ IPTG, respectively, yielded a level of CyaB approximately equivalent to that of the wild-type strain; expression of $c y a B_{\Delta 1-216}$ from the pMMB plasmid, which has higher tac promoter activity, required $10 \mu \mathrm{M}$ IPTG. Samples were normalized based on bacterial number. Molecular weight size standards are indicated. (c) cAMP reporter activity (corrected for $\mathrm{CyaB}$ protein levels) in the $c y a A$ or $c y a A B$ mutants carrying either an empty vector $(\mathrm{V})$, pMMBV2 expressing $c y a B$ or $c y a B_{\Delta 1-17}$, or pMMB

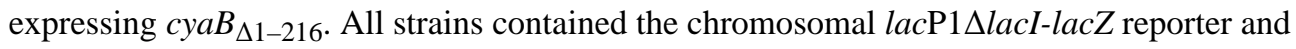


were grown to mid-exponential growth phase with amount of IPTG indicated above. Equivalent samples were assayed for $\beta$-galactosidase activity and analyzed by quantitative immunoblot. CyaB levels were normalized based on the cyaA mutant carrying $\mathrm{V}$ and used to calculate relative activity. Bars represent the mean \pm SEM of at least three independent experiments. The asterisk $(*)$ indicates that the values for the indicated strains were significantly different $(P<0.0001)$ when compared pairwise to the value for the cyaA mutant carrying $\mathrm{V}$. 


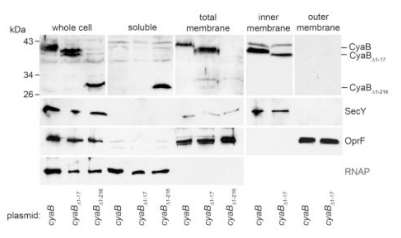

Figure 2. The MASE2 domain is required for $\mathrm{CyaB}$ membrane localization

Bacterial cell fractions from PAKcyaAB expressing wild-type $\mathrm{CyaB}_{\text {or }} \mathrm{CyaB}_{\Delta 1-17}$ from pMMBV2, or $\mathrm{CyaB}_{\Delta 1-216}$ from pMMB. Strains were grown to mid-exponential growth phase with $50(\mathrm{CyaB}), 20\left(\mathrm{CyaB}_{\Delta 1-17}\right)$ or $10\left(\mathrm{CyaB}_{\Delta 1-216}\right) \mu \mathrm{M}$ IPTG. Whole-cell lysates, soluble (cytoplasmic-periplasmic) fractions and membrane (total, inner, and outer) fractions were subjected to SDS-PAGE and probed with antibody specific for CyaB, SecY, OprF or RNAP $\beta$ subunit. For CyaB immunoblots, $15 \mu \mathrm{l}$ of whole-cell lysate or $15 \mu \mathrm{g}$ of fractionated protein was loaded; for all other immunoblots, $2 \mu \mathrm{l}$ of whole-cell lysate or $2 \mu \mathrm{g}$ of fractionated protein was loaded. RNAP $\beta$ subunit $(\sim 150 \mathrm{kDa})$ served as a control for cytoplasmic localization; SecY ( $\sim 50 \mathrm{kDa})$ and OprF ( 34 kDa) served as inner and outer membrane fraction markers, respectively. Molecular weight size standards are indicated. Samples were fractionated at the same time, but were immunoblotted on different days. The immunoblots are representative of at least two independent experiments. 

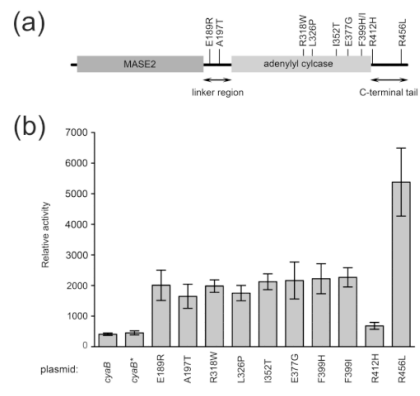

Figure 3. Analysis of CyaB mutants with increased enzyme activity

(a) Diagram indicating the site of $\mathrm{CyaB}$ missense mutations obtained in the screen for elevated cAMP-dependent reporter activity. (b) cAMP reporter activity (corrected for $\mathrm{CyaB}$ protein levels) in the $c y a A B$ mutant carrying pMMBV2 expressing either $c y a B$, a $c y a B$ wildtype clone from the screening strain $\left(c y a B^{*}\right)$, or the indicated $c y a B$ mutant. All strains contained the chromosomal lacP1 $\mathrm{PlacI}$-lacZ reporter. Strains were grown to midexponential growth phase in LB with $5 \mathrm{mM} \mathrm{NaCl}$ (low salt) and $50 \mu \mathrm{M}$ IPTG. Equivalent samples were assayed for $\beta$-galactosidase activity and analyzed by quantitative immunoblot. CyaB levels were normalized based on the $c y a A B$ mutant carrying pMMBV2-cyaB and used to calculate relative activity. Bars represent the mean \pm SEM of three independent experiments. Values for all CyaB mutants (except R412H)) were significantly different $(P \leq$ 0.043 ) when compared pairwise to the value for the $c y a A B$ mutant carrying pMMBV2-cyaB. 

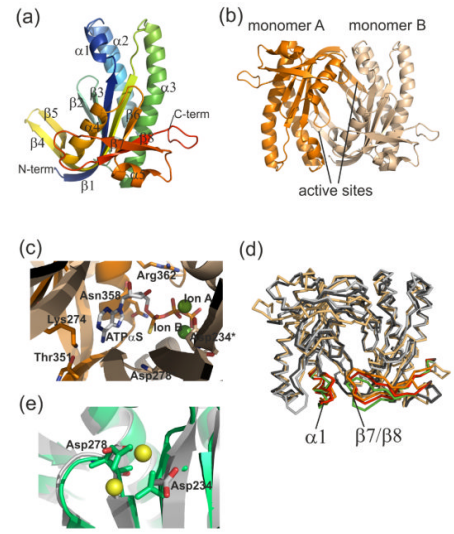

Figure 4. Crystal structure of the CyaB catalytic domain

(a) Overall structure of the $\mathrm{CyaB}$ monomer with labelled secondary structure elements. The connectivity is indicated through rainbow coloring from blue $(\mathrm{N}$-terminus) to red $(\mathrm{C}$ terminus). (b) Overall structure of the catalytic $\mathrm{CyaB}$ homodimer, with chain $\mathrm{A}$ and $\mathrm{B}$ colored orange and light orange, respectively. The locations of the two active sites at the dimer interface, derived through comparison to other Class III ACs, are indicated. (c) Active site of $\mathrm{CyaB}$, with ATP $\alpha \mathrm{S}$ and the two divalent ions A and B modelled into the substrate binding pocket through overlay with a CyaC/ATP $\alpha \mathrm{S}$ complex (PDB ID 1WC1). Conserved Class IIIb catalytic residues are shown as sticks and labelled (* indicates residues from monomer B). (d) Comparison of CyaB (light orange) with the open (light grey; PDB ID $1 \mathrm{WC} 0$ ) and closed (dark grey; 1WC1) conformations of CyaC. The structural elements showing major movements during catalysis are highlighted (CyaB: dark orange; CyaC open: green; CyaC closed: red) and labelled. (e) Close view of the empty CyaB (grey) active site overlaid with the CyaC/ATPaS complex (green; PDB ID 1WC1). The magnesium ions from the $\mathrm{CyaC}$ structure are shown as yellow spheres, and the Asp of CyaB are labelled and colored according to atom type. The Asp side chains of CyaB are partially and fully rotated, respectively, opening up the ion binding sites. In CyaC, in contrast, the Asp side chains are oriented toward the ions and coordinate each magnesium with one oxygen atom. 
(a)

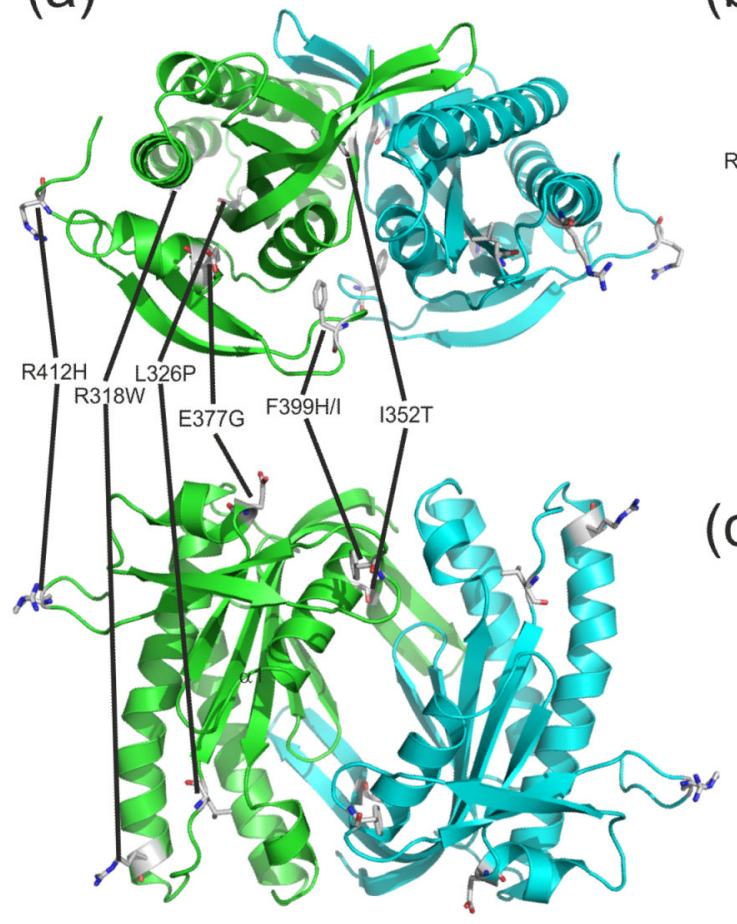

(b)

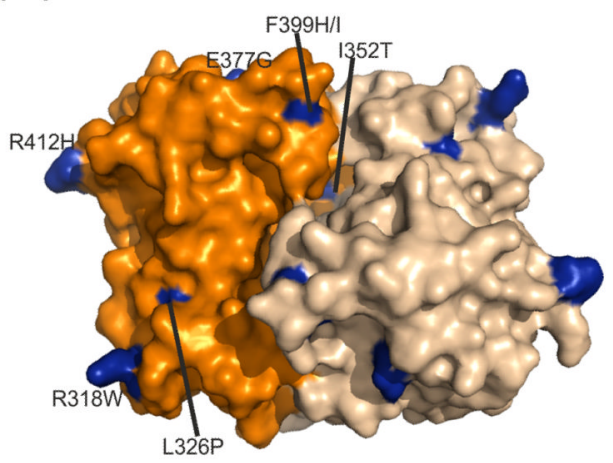

(c)

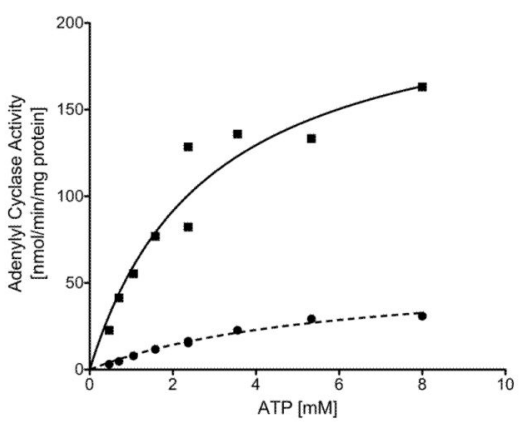

Figure 5. Structural analysis of residues involved in $\mathrm{CyaB}$ regulation (a) Activating mutations identified in a genetic screen are shown as sticks in the front and top views of the CyaB crystal structure, and (b) as blue patches on the surface of the structure. Amino acids at these positions and the substituting amino acid are indicated with one-letter codes. (c) Comparison of specific activities of $\mathrm{CyaB}_{220-416}$ wildtype $(\bullet)$ and the $\mathrm{CyaB}_{220-416}$-Leu326Pro mutant (-) determined at $10 \mathrm{mM} \mathrm{Mn}^{2+}$ and increasing ATP concentrations. 
(a)
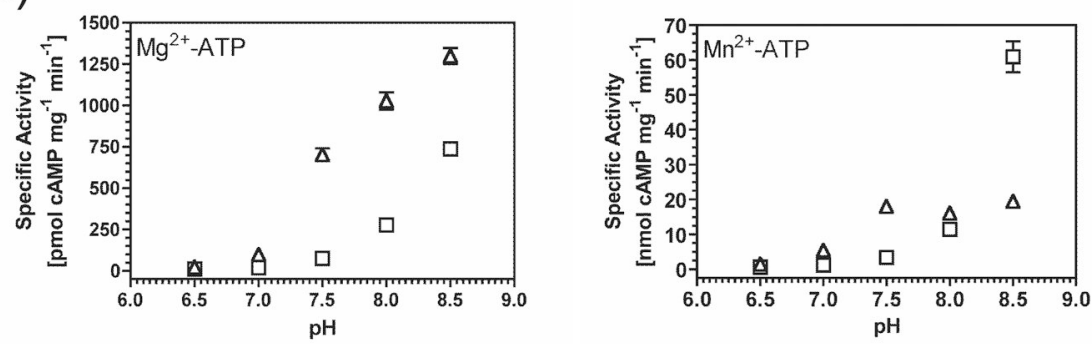

(b)

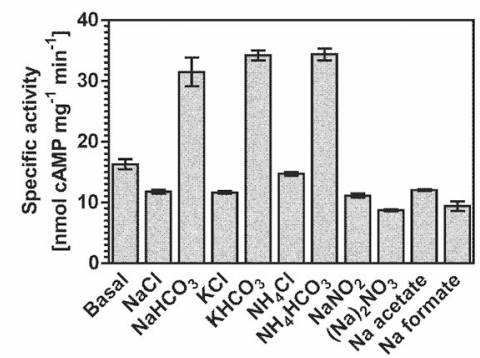

(c)

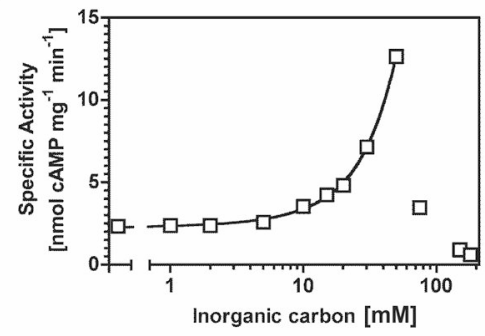

Figure 6. Regulation of CyaB by bicarbonate

(a) $0.17 \mu \mathrm{M}\left(\mathrm{Mn}^{2+}\right.$-ATP $)$ or $13.7 \mu \mathrm{M}\left(\mathrm{Mg}^{2+}-\mathrm{ATP}\right) \mathrm{CyaB}_{217-463}$ was assayed at varying $\mathrm{pH}$ at $40^{\circ} \mathrm{C}$ with $0.2 \mathrm{mM}\left(\mathrm{Mn}^{2+}-\mathrm{ATP}\right)$ or $1 \mathrm{mM}\left(\mathrm{Mg}^{2+}-\mathrm{ATP}\right)$ substrate in the presence of 20 $\mathrm{mM} \mathrm{NaCl}(\square)$ or $\mathrm{NaHCO}_{3}{ }^{-}(\Delta)$. (b) $0.17 \mu \mathrm{M} \mathrm{CyaB}_{217-463}$ was assayed at $\mathrm{pH} 7.5$, with 30 $\mathrm{mM}$ salt at $40^{\circ} \mathrm{C}$ and $0.2 \mathrm{mM} \mathrm{Mn}^{2+}$-ATP as substrate. (c) $0.17 \mu \mathrm{M} \mathrm{CyaB}_{217-463}$ was assayed at $\mathrm{pH} 7.5$ and $40^{\circ} \mathrm{C}$ with varying concentrations of $\mathrm{NaHCO}_{3}$ and $\mathrm{NaCl}$ to maintain a constant $180 \mathrm{mM}$ total salt concentration, and $0.2 \mathrm{mM} \mathrm{Mn}^{2+}$-ATP as substrate. The drop of activity beyond $50 \mathrm{mM} \mathrm{NaHCO}_{3}$ is likely a precipitation artefact typically observed for $\mathrm{Mn}^{2+}$ at high $\mathrm{NaHCO}_{3}$ concentrations. 
(a)

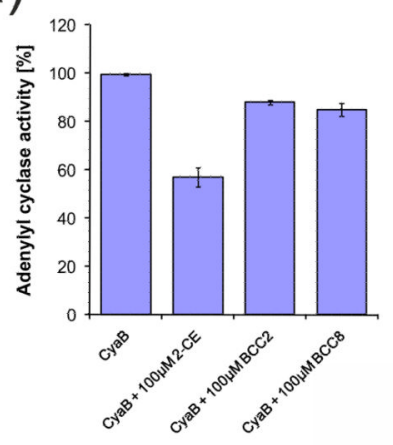

(C) (b)

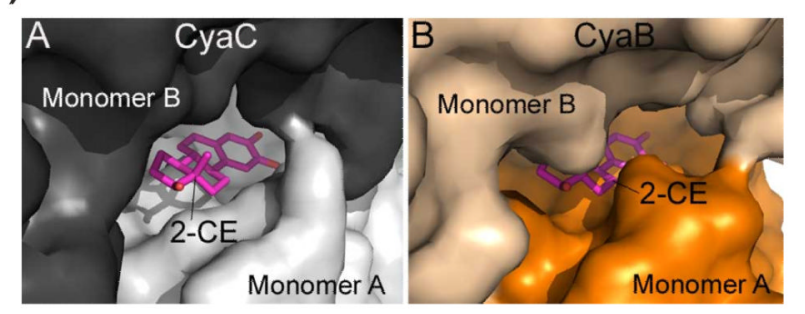

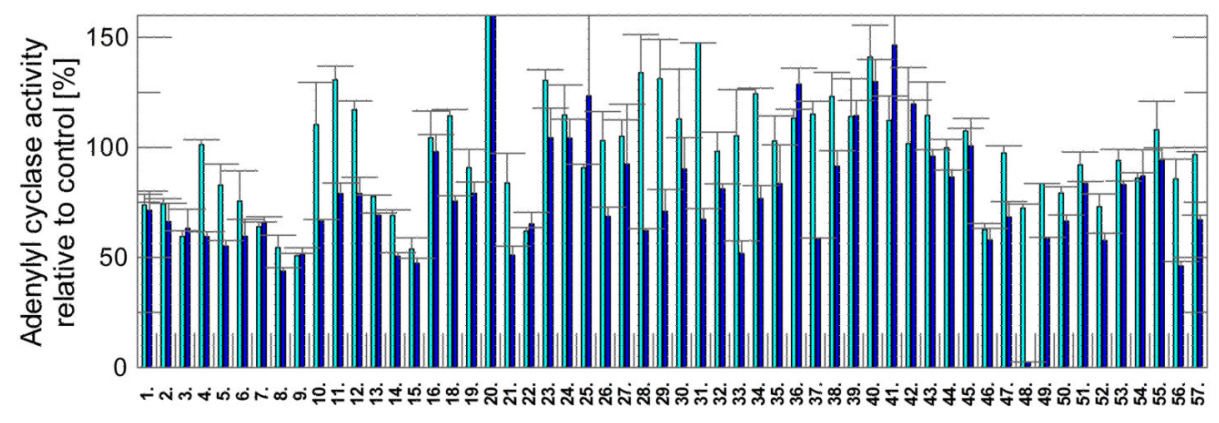

KH7.1xx Compound no.

(d)

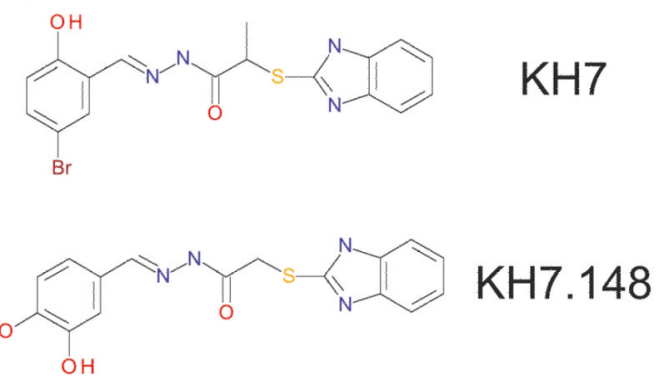

(e)

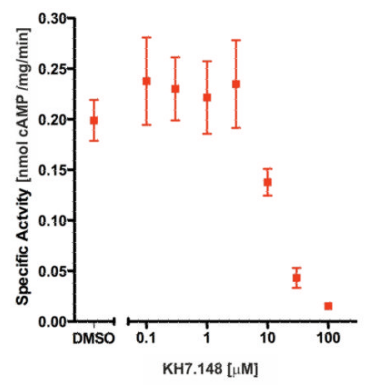

Figure 7. Regulation of CyaB by small molecule drugs

(a) Inhibition of $\mathrm{CyaB} A C$ activity by $100 \mu \mathrm{M} 2-\mathrm{CE}, \mathrm{BCC} 2$, and $\mathrm{BCC} 8$, respectively. (b) Comparison of the $\mathrm{CE}$ binding sites of $\mathrm{CyaC}$ (A) and $\mathrm{CyaB}(\mathrm{B})$. The inhibitor was put into the corresponding $\mathrm{CyaB}$ site based on an overlay with the crystal structure of the $\mathrm{CyaC} / \mathrm{CE}$ complex (PDB ID 2BW7). (c) Screening for CyaB inhibitors by testing a library of KH7 derivatives. AC assays were performed with $1 \mathrm{mM}$ ATP in the presence of $10 \mu \mathrm{M}$ (blue bars) or $100 \mu \mathrm{M}$ (red bars) drug. (d) Chemical structures of KH7 and KH7.148. (e) Doseresponse curve for inhibition of $\mathrm{CyaB}$ by $\mathrm{KH} 7.148$, indicating an $\mathrm{IC}_{50}$ of $\sim 10 \mu \mathrm{M}$. 
Table I

CyaB mutants with altered cAMP reporter activity.

\begin{tabular}{lc}
\hline mutation $^{*}$ & number of clones \\
\hline E189R & 8 \\
E377G & 7 \\
L326P & 3 \\
F399I & 3 \\
R318W & 2 \\
A197T & 1 \\
I352T & 1 \\
F399H & 1 \\
R412H & 1 \\
R456H & 1 \\
\hline
\end{tabular}

amino acid position 
Table II

Crystallographic data and refinement statistics

\begin{tabular}{|c|c|}
\hline & CyaB \\
\hline Space group & $\mathrm{P} 2$ \\
\hline Unit cell constants & $\mathrm{a}=51.4 \AA, \mathrm{b}=36.3 \AA, \mathrm{c}=94.8 \AA ; \beta=98.76^{\circ}$ \\
\hline Resolution limit & $1.5 \AA$ \\
\hline Unique reflections & 50946 \\
\hline$<\mathrm{I} / \sigma>(a)$ & $20.6(4.6)$ \\
\hline Completeness $^{(a)}$ & $91.2 \%(61.4 \%)$ \\
\hline $\mathrm{R}_{\text {merge }}(a)$ & $5.4 \%(36.4 \%)$ \\
\hline Refinement resolution & $47.8-1.5 \AA$ \\
\hline Total reflections used & 48397 \\
\hline $\mathrm{R}_{\text {cryst }} / \mathrm{R}_{\text {free }}(b)$ & $18.6 \% / 23.0 \%$ \\
\hline Atoms: protein / solvent + glycerol & $3054 / 323$ \\
\hline R.m.s.d. bond lengths & $0.028 \AA$ \\
\hline R.m.s.d. Bond angles & $2.4^{\circ}$ \\
\hline Average B-factor: protein / solvent + glycerol & $20.8 \AA^{2} / 32.1 \AA^{2}$ \\
\hline
\end{tabular}

